\title{
CORONAVIRUS INDUCED ENCEPHALOMYELITIS: AN IMMUNODOMINANT CD4+ - T CELL SITE ON THE NUCLEOCAPSID PROTEIN CONTRIBUTES TO PROTECTION
}

\author{
Helmut Wege, Andreas Schliephake, Heiner Körner, \\ Egbert Flory, and Hanna Wege \\ Institute of Virology and Immunobiology, \\ Versbacher Strasse 7, D-97078 Würzburg, Germany
}

\section{SUMMARY}

In this communication we present clear evidence, that the N-protein of MHV-JHM contains immunodominant $\mathrm{CD} 4+\mathrm{T}$-cell sites. These sites were recognized by the immune system of virus infected Lewis rats. In previous investigations we have shown, that CD4+ Tcell lines with specificity for defined viral proteins can be selected from diseased Lewis rats and mediate protection, if transferred to otherwise lethally infected animals 1 . To define regions of the N-protein, which are immunodominant for the T-cell response, we employed bacterially expressed $\mathrm{N}$-protein and truncated subfragments of $\mathrm{N}$ as an antigen. We demonstrate, that $\mathrm{T}$ cells from MHV-JHM infected, diseased Lewis rats recognized with high prevalence the carboxyterminal subfragment $\mathrm{C} 4-\mathrm{N}$ (95 aa) and to some extent the adjacent $\mathrm{C} 3-\mathrm{N}$ protein. The same results were obtained with T-cells derived from rats immunized with bacterially expressed $\mathrm{N}$-protein or from animals vaccinated by a stable $\mathrm{N}$-protein expressing vaccinia recombinant. Finally, transfer of CD4+ line T-cells to MHV-JHM infected rats specific for C4$\mathrm{N}$ mediated protection against acute disease.

\section{INTRODUCTION}

Murine coronavirus infections of the central nervous system are of great interest to analyse mechanisms of inflammatory demyelination and virus persistency 2 . In Lewis rats, we observed different courses of an encephalomyelitis 3,4,5,6,7. Acute disease developed within a short incubation time and was associated with extensive necrotic lesions affecting predominantly the gray matter. The hallmark of the subacute demyelinating encephalomyelitis (SDE), which occured within several weeks to months p.i., were inflammatory demyelinating lesions confined to the white matter. The development of these lesions in MHV-JHM infected Lewis rats was mainly triggered by immune reactions against viral antigens. Therefore, our interest is focused on the structure and function of coronavirus proteins and their interactions with the immune system. We initiated studies to define the role of specific T-cell response during acute and subacute disease induced by MHV-JHM in Lewis-rats 1.

To investigate the antiviral CD4 $+\mathrm{T}$-cell response, we stimulated spleen-lymphocytes from diseased rats in culture with virus antigen and tested their specificity for defined viral proteins after expansion of the culture. As a prerequirement for these studies, we expressed S- 
or N-protein in bacteria. The bacterially expressed proteins were purified and employed as antigens. The results of T-cell proliferation assays with splenocyte cultures derived from diseased rats indicated that a strong $\mathrm{T}$-cell response against nucleocapsid protein $\mathrm{N}$ was detectable already early in infection. By contrast, spike protein specific responses could only be demonstrated in cultures derived from rats suffering from SDE. For further studies we established CD4+ T-cell lines against these proteins. Transfer experiments were performed with rats, which had been infected with a normally lethal dose of MHV-JHM. Our results indicated, that activated $\mathrm{N}$ - or S- specific CD4t- $\mathrm{T}$ cells can mediate protection and contribute to clearance of virus from the brain 1 . Depletion of CD8+ T-cells by monoclonal antibodies did not diminish the protection confered by transfer of virus protein specific CD4+ T-cells.

A number of studies on cell mediated immunity in human and animal disease models have confirmed the pivotal role of CD4+ T-cells for the outcome of infection. The biological significance of each virus protein for the cellular and humoral immune response varies with the virus-host system taken into consideration. In MHV-JHM infected Lewis rats, the major T-cell response was specific for $\mathrm{N}$-protein. In this communication we demonstrate, that these dominant $\mathrm{N}$-specific $\mathrm{T}$ cell sites were located near to the carboxyterminal part of the nucleocapsid protein. This finding could be of general importance for the development of the immune response during coronavirus infections.

\section{RESULTS}

\section{Expression of $\mathbf{N}$-protein Subfragments}

To define the antigenic domains on this protein, we expressed the cDNA of $\mathrm{N}$ as a betagalactosidase fusion protein employing the $\mathrm{pROS}$ vector system. A clone containing the entire MHV-JHM N gene was provided by T. Raabe and S. Siddell as a derivative of pAT153 (Raabe, diploma thesis, Würzburg 1987). The cDNA (bp 96-1546) was cloned into the expression vector $\mathrm{pROS} 8$. This vector system allows the expression of genes as a fusion protein with beta - galactosidase. Defined truncated subfragments of the N-cDNA were produced by digestion with restriction enzymes and then subcloned into pROS. The panel of subfragments employed for the following studies is displayed in figure 1. A0-N denotes the nearly complete N-gene, A1-N, A2-N, C3-N and C4-N are designations of N-subfragments arranged from the $\mathrm{N}$-terminal to the $\mathrm{C}$-terminal end including the stop codon of the $\mathrm{N}$-gene. The expressed $\mathrm{N}$-protein subfragments were purified from bacterial lysates by combined steps of gel electrophoresis and elution. For usage as a T-cell antigen, the proteins were transferred to nitrocellulose and processed as described previously 1 .

\section{Immunogenicity of $\mathrm{N}$-protein subfragments}

As a first step we investigated the immunogenicity of the bacterially expressed N-protein and its subfragments. For this purpose, proliferation assays with lymphocyte cultures were performed. Rats were intracerebrally infected with MHV-JHM and splenocyte cultures were established from diseased animals. The proliferation assays were performed after one cycle of restimulation with virus antigen. In parallel, rats were immunized with purified $\mathrm{N}$-protein, which had been expressed in bacteria. Furthermore, a $\mathrm{N}$-specific immune response was elicited by vaccination with a vaccinia virus recombinant, which expresses the MHV-JHM N-protein. Independent of the method of immunization, the carboxyterminally located fragment (C4-N) induced in all cases a very strong $\mathrm{T}$-cell proliferation. A typical result obtained with T-cells from SDE rats is displayed in figure 2. C4-N is a polypeptide of 95 amino acids at the carboxyterminal end of $\mathrm{N}$ (figure 1). A weak T-cell response was observed with $\mathrm{C} 3-\mathrm{N}$, no specific T-cell response was obtained with A1-N and A2-N. However, all these subfragment proteins were immunogenic, because the sera of the rats contained specific antibodies. This humoral response was demonstrated by Elisa and immunostaining of Western-blots. 


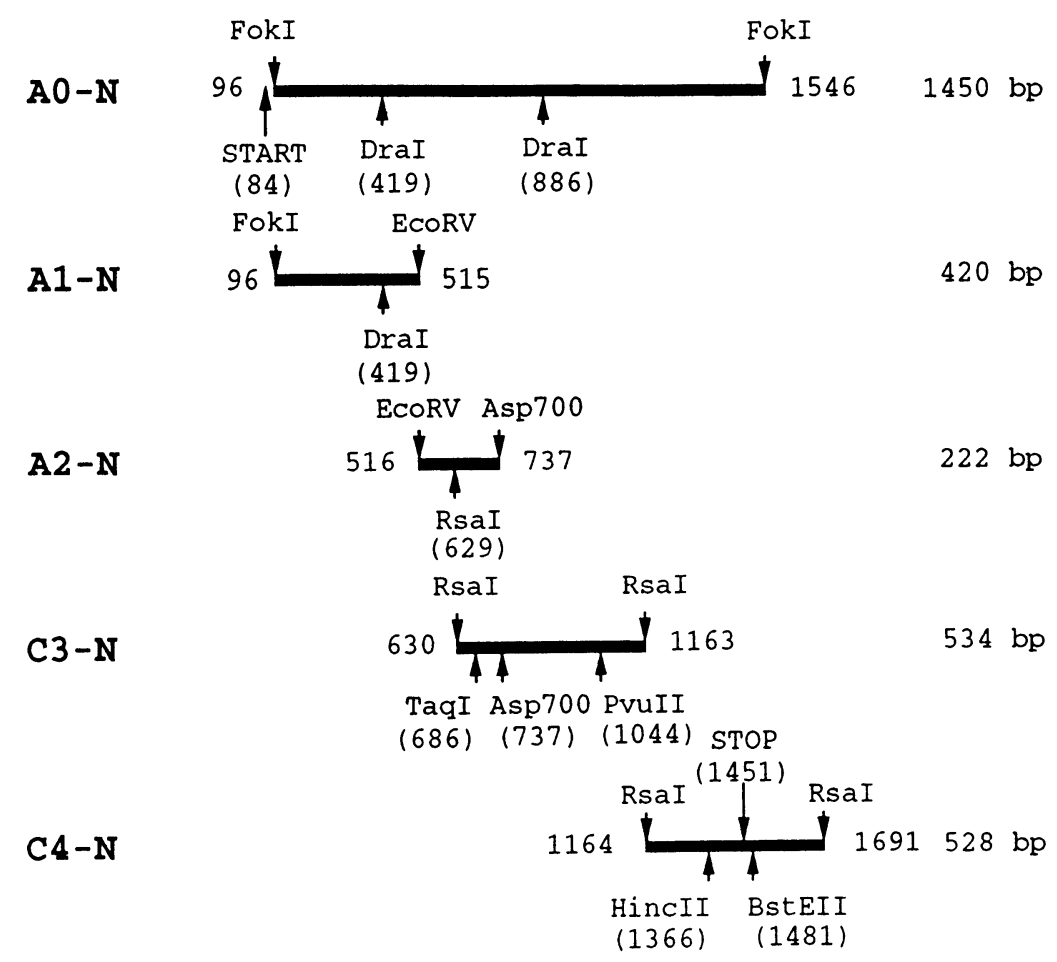

Figure 1. Scheme of N-cDNA-fragments derived by restriction enzyme digestion for expression in pROS. A0-N denotes the neartly full length gene, A1-N, A2-N, C3-N and C4-N are smaller fragments in the direction from the $\mathrm{N}$-terminal to the $\mathrm{C}$-terminal end of the gene. The length (bp) of the cDNA-fragments is indicated on the right side.

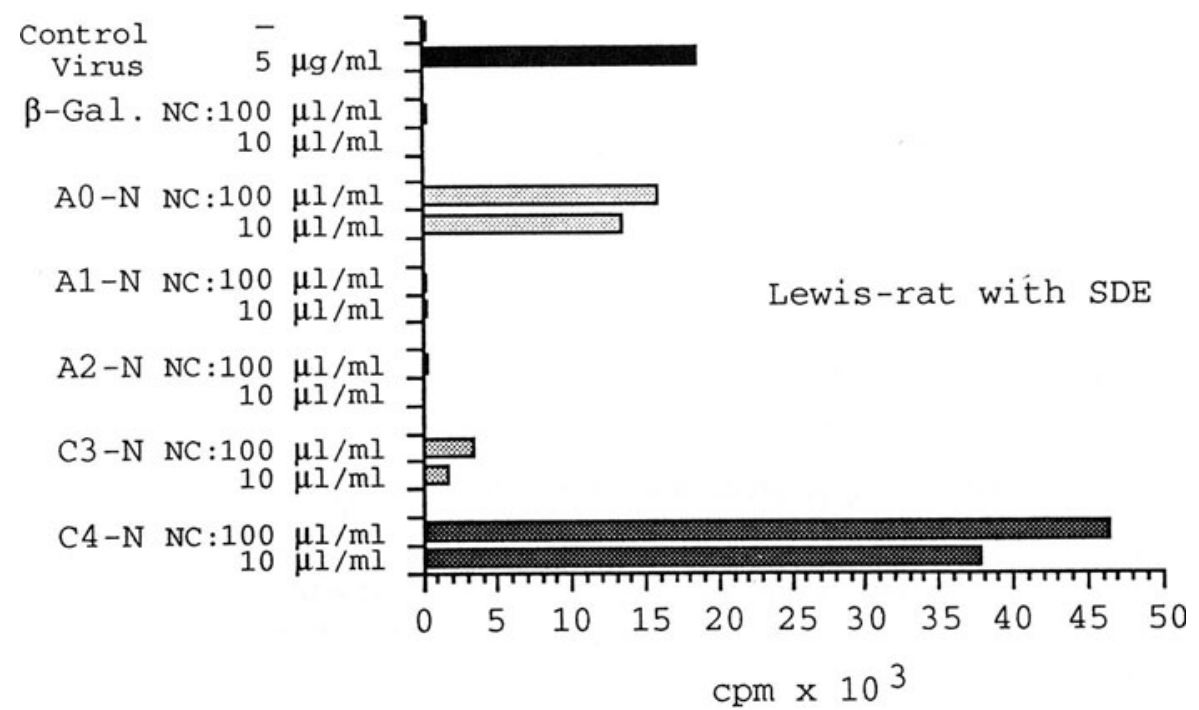

Figure 2. Lewis rat with SDE: Specificity of the T-cell response for Nucleocapsid and $\mathrm{N}$-fragments expressed in pROS. The bacterially expressed proteins were separated by SDS-PAGE before electrophoretic transfer to nitrocellulose (NC). The protein bands were excised, dissolved in DMSO and precipitated with a carbonate buffer 1 . Splenocytes from a rat with SDE were restimulated once in culture with virus antigen before proliferation assays were performed employing the $\mathrm{N}$-fragment antigens. Virus antigen consisted of sucrose density gradient purified virions. 


\section{Isolation of $\mathrm{N}$-subfragment specific $\mathrm{CD}^{+}+\mathrm{T}$-cell lines}

To evaluate further the immunological significance of the carboxyterminal region, we established a panel of CD4+ T-cell lines specific for each of these subfragments. For this purpose, rats were immunized with purified subfragment proteins and lymphocyte cultures were established from lymph nodes as described by Körner et al. ${ }^{7}$ by alternating cycles of restimulation with antigen and expansion with interleukin containing media. An example for the antigen specificity is shown in figure 3 for the T-cell line specific for the subfragment $\mathrm{C} 4$ $\mathrm{N}$. The line recognizes besides the $\mathrm{C} 4-\mathrm{N}$ subfragment antigen the full length $\mathrm{A} 0-\mathrm{N}$ and purified virus antigen. In addition, beta-galactosidase induces also proliferation, because the plasmid constructs contain the appropriate sequence fused to this gene. No cross reactivity was detected employing other $\mathrm{N}$-subfragment antigens. Similar results were obtained with the T-cell lines $\mathrm{A} 1-\mathrm{N}, \mathrm{A} 2-\mathrm{N}$ and $\mathrm{C} 3-\mathrm{N}$.

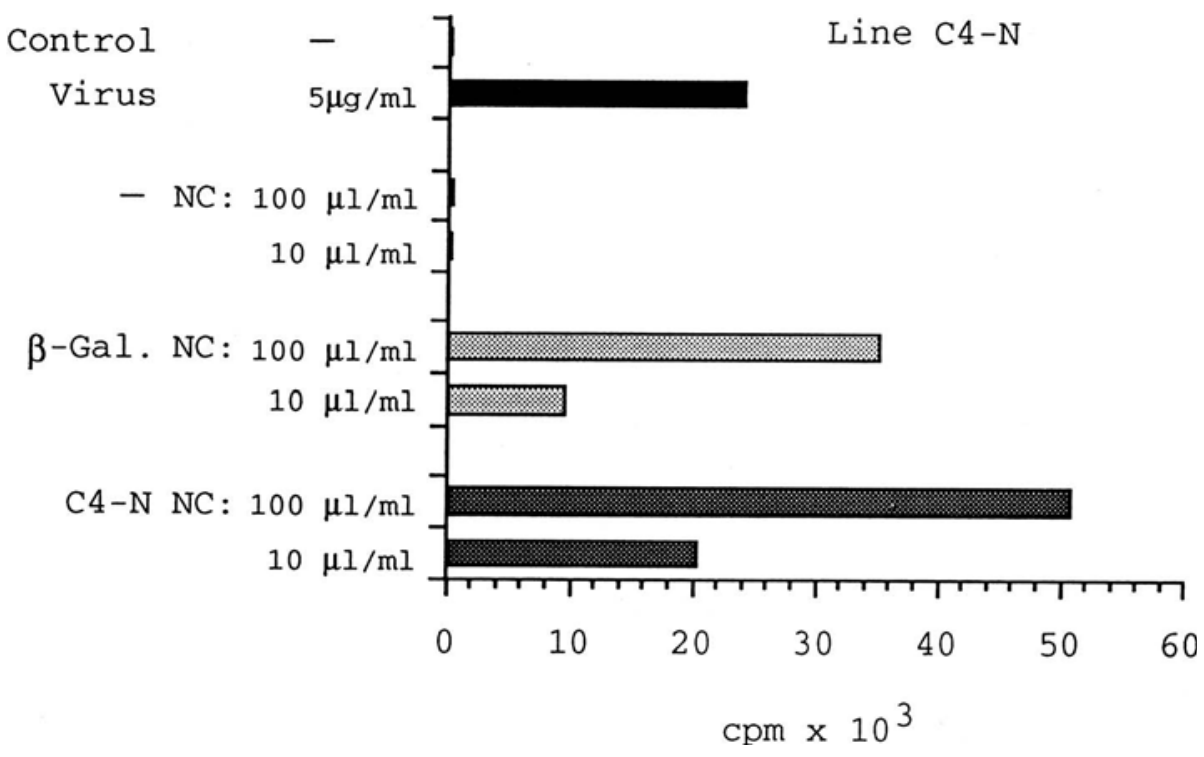

Figure 3. Antigen-specificity of the T-cell line $\mathrm{C} 4-\mathrm{N}$ in a proliferation assay. The antigen consisted of a microparticulate nitrocellulose suspension (NC) as described in figure 2 . Virus was purified by sucrose density centrifugation.

\section{Transfer of N-protein Subfragment specific CD4+ T-Cell Lines to MHV-JHM infected Lewis-Rats}

In order to demonstrate the biological effects of these T-cell lines, we performed the following transfer experiments. The rats were infected one day after intraperitoneal transfer of $5 \times 106$ activated line T-cells. At the timepoint of intracerebral infection with MHV-JHM, the rats were 8-10 days old. The results are summarized in table 1. T-cell lines specific for A0-N as well as for C4-N polypeptide can mediate protection by adoptive transfer against an otherwise lethal MHV-JHM infection. None or little protective effect was induced by transfer of A1-N, A2-N and C3-N. These results indicate, that the carboxy-terminal region of the Nprotein comprises T-cell epitopes which are of biological importance for the outcome of infection. 
Table 1. Disease course after transfer of CD4+- T-cell lines specific for truncated N-proteins

\begin{tabular}{c|c|c|c}
\hline T-cell line & \multicolumn{1}{c}{$\begin{array}{c}\text { Diseased/ } \\
\text { Total }\end{array}$} & \multicolumn{1}{c}{$\begin{array}{c}\text { Dead/ } \\
\text { Total }\end{array}$} & \multicolumn{1}{c}{$\begin{array}{c}\text { Incubation } \\
\text { time (Days) }\end{array}$} \\
transferred & $9 / 9$ & $9 / 9$ & $5-13$ \\
Control & $2 / 9$ & $2 / 9$ & 12 \\
A0-N & $7 / 7$ & $7 / 7$ & $4-7$ \\
A1-N & $8 / 8$ & $8 / 8$ & $4-10$ \\
A2-N & $12 / 12$ & $12 / 12$ & $5-18$ \\
C3-N & $7 / 11$ & $7 / 11$ & $10-24$ \\
C4-N & &
\end{tabular}

Transfer of $5 \times 10^{6}$ line T-cells was performed i.p. two days before infection. The Lewis-rats were infected i. c. with 600 plaque forming units of MHV-JHM, when 8-10 days old.

\section{DISCUSSION}

The relative importance of the different virus proteins for cellular and humoral immunity during coronavirus infections is not yet known in detail. The results described here indicate, that the carboxyterminal region of the $\mathrm{N}$-protein comprises $\mathrm{T}$-cell epitopes which are of biological significance for the outcome of infection. Although the surface proteins of coronaviruses are of major impact for virus-induced immunity, the role of the $\mathrm{N}$-protein has to be considered as an indispensible component in this network.

The N-protein is a highly abundant, relatively conserved antigen, which is already accumulated before release of mature virus ${ }^{9}$. Therefore, a cellular immune response elicited early in infection by internal virus proteins could be an important defense mechanism since lymphokines produced by $\mathrm{CD} 4+\mathrm{T}$-cells can trigger an array of specific immune reactions. Activated T-cells can promote B-cell responses independently of their antigen specificity. It has been shown recently, that immunization with a synthetic peptide comprising an irrelevant $T$ helper cell epitope in combination with a S-protein specific B-cell epitope can induce strong protection against disease 10 . In MHV-JHM infected rats, a detectable S-specific T-cell response appears to be induced only late in the course of infection, when rats develop a subacute demyelinating encephalomyelitis 1 . During the acute stage of disease, an efficient elimination of virus infected cells by cellular immune response is probably the dominant defense mechanism. The $S$-protein is the dominant antigen for antibody response which inhibits the infectivity of the virus and prevents cell fusion. Provided that the organism overcomes the acute stage without complete elimination of the virus, the disease process can run a chronic course. Our data imply, that the pathogenesis of inflammatory demyelination involves a disbalance between antibody mediated virus specific immune responses and a downregulation of the expression of viral surface proteins (Flory et al., this vol.) 7 .

The relative contribution of CD4+ T-cells (helper/inducer) and CD8+ T-cells (CTL) for virus elimination differs with the virus-host system employed. Many studies on cellular immunity suggest that the major T-cell response is MHC class II restricted. For coronavirus infections in mice, both $\mathrm{CD} 4+$ and $\mathrm{CD} 8+\mathrm{T}$-cells have to interact to eliminate virus from the central nervous system, although virus specific CD4+ T-cells can mediate protection from acute disease by a DTH-like reaction $2,11,12$. Results from our transfer experiments imply, that in Lewis rats activated $\mathrm{N}$-specific CD4+ T-cells alone have the biological potential to eradicate virus from brain tissue. It had been shown for other virus-host systems, that CD4+ $T$-cells can display an antigen specific cytolytic potential 13 . However, during the natural course of infection the speed and rate of $\mathrm{CD} 4+\mathrm{T}$-cell activation may be insufficient to effect virus elimination alone. We anticipate, that also in Lewis-rats the observed $\mathrm{N}$-specific CD4+ Tcell response plays a pivotal role to trigger virus elimination in concert with other components. At present, in the rat system no direct proof for virus specific CTL activity is available. On the other hand, studies of the lymphocyte population dynamics demonstrated the presence of $\mathrm{CD} 8+\mathrm{T}$-cells in the central nervous system during recovery from acute disease 14 . Thus, further studies on the relative contribution of $\mathrm{CD} 4+$ and $\mathrm{CD} 8+\mathrm{T}$-cells in different coronavirus infections are of great interest. 
In a number of virus systems the induction of CTL by nucleoprotein was demonstrated $15,16,17$. Despite of these findings, immunization against nucleocapsid proteins alone was in most virus-host systems not sufficient to confer protection 15 . Vaccination of cats against FIPvirus with a vaccinia recombinant expressing $\mathrm{N}$-protein had no protective effect 18 . Our attempts, to vaccinate Lewis-rats against $\mathrm{N}$ before challenge, were not succsessfull despite of the capacity to induce a specific T-cell response (Flory et al., this vol.). The insufficient protective effect of $\mathrm{N}$-protein could be explained by a low CTL activity and the mode of antigen presentation or processing. Although the passive transfer of specific line T-cells does not represent the entire reaction of the immune system during a natural infection or immunization, the results from such experiments clearly illustrate their biological potential.

In this context, Stohlman et al. 19 have identified recently a carboxyterminally located region of the N-protein from MHV-A59, which is important for the induction of a CTL response in mice. Furthermore, the N-protein of IBV contains a T-cell site which enhanced protection 20,21. Such T-cell responses could complement and interact with the important surface protein specific immune reactions to provide protection or to determine the disease course of the infected organism.

\section{ACKNOWLEDGEMENTS}

The work was supported by the Hertie Stiftung and Deutsche Forschungsgemeinschaft.

\section{REFERENCES}

1. Körner, H., A. Schliephake, J. Winter, F. Zimprich, H. Lassmann, J. Sedgwick, S. Siddell, and H. Wege. J. Immunol. 147(7): 2317-23, 1991.

2. Kyuwa, S. and S. A. Stohlman. Seminars in Virol. 1: 273- 280, 1990.

3. Nagashima, K., H. Wege, R. Meyermann, and V. ter Meulen. Acta Neuropath. 44: 6370, 1978.

4. Watanabe, R., H. Wege, and V. ter Meulen. Nature 305: 150-153, 1983.

5. Watanabe, R., H. Wege, and V. ter Meulen. Lab. Invest. 57(4): 375-84, 1987.

6. Wege, H., R. Watanabe, and V. ter Meulen. J. Neuroimmunol. 6: 325-336, 1984.

7. Zimprich, F., J. Winter, H. Wege, and H. Lassmann. Neuropath. and Appl.Neurobiol. 17: 469-484, 1991.

8. Bröker, M. Gene Anal. Tech. 3: 53-57, 1986.

9. Parker, M. M. and P. S. Masters. Virol. 179(1): 463-8, 1990.

10. Koolen, M. J., M. A. Borst, M. C. Horzinek, and W. J. Spaan. J. Virol. 64(12): 6270-3, 1990.

Anthony, and J. G. Keck. Virol. 189(1): 217-24, 1992.

11. Sussman, M. A., R. A. Shubin, S. Kyuwa, and S. A. Stohlman. J. Virol. 63(7): 30516, 1989.

12. Williamson, J. S., and S. A. Stohlman. J. Virol. 64(9): 4589-92, 1990.

13. Erb, P., D. Grogg, M. Troxler, M. Kennedy, and M. Fluri. J. Immunol. 144(3): 79095, 1990.

14. Dörries, R., S. Schwender, H. Imrich, and H. Harms. Immunology 74(3): 539-45, 1991.

15. Stitz, L., C. Schmitz, D. Binder, R. Zinkernagel, E. Paoletti, and H. Becht. J. Gen. Virology 71: 1169-79, 1990.

16. Yamaguchi, K., N. Goto, S. Kyuwa, M. Hayami, and Y. Toyoda. J Neuroimmunol. 32(1): 1-9, 1991.

17. Yasukawa, M., A. Inatsukio, and Y. Kobayashi. J. Immunol. 140: 3419-25, 1988.

19. Stohlman, S. A., S. Kyuwa, M. Cohen, C. Bergmann, J. M. Polo, J. Yeh, R. 18. Vennema, H., R. de Groot, D. A. Harbour, M. C. Horzinek, and W. J. Spaan. Virology 181(1): 327-35, 1991.

20. Boots, A. M., T. B. Benaissa, W. Hesselink, E. Rijke, C. Schrier, and E. J. Hensen. Vaccine 10(2): 119-24, 1992.

21. Boots, A. M., J. G. Kusters, N. J. van, K. A. Zwaagstra, E. Rijke, B. van der Zeijst, and E. J. Hensen. Immunology. 74(1): 8-13, 1991. 